\title{
Galleguismo y quijotismo: a propósito del tricentenario del Quijote*
}

\author{
JESÚS PÉREZ-MAGALLÓN**
}

\begin{abstract}
Resumen
En 1905 se cumplía el tercer centenario de la publicación de El ingenioso hidalgo don Quijote de la Mancha, compuesto por Miguel de Cervantes Saavedra. Después de las experiencias de otras celebraciones en el último cuarto del siglo XIX, en particular la de Calderón en 1881, algunos intelectuales españoles proponen una conmemoración grandiosa y espectacular para el tercer centenario del Quijote, idea que retoman los políticos de Madrid. En este artículo vamos a explorar el contexto nacionalista, político y cultural de la propuesta de celebración, pero sobre todo vamos a estudiar cómo es recibida esa propuesta en una nacionalidad histórica como Galicia.
\end{abstract}

Palabras clave: Cervantes; tricentenario; Quijote; nacionalismo; regionalismo; Galicia; galleguismo.

Title: Galleguismo and Quijotismo: on Quixote's Tercentenary

\begin{abstract}
1905 was the tercentenary of the publishing of El ingenioso hidalgo don Quijote de la Mancha, by Miguel de Cervantes Saavedra. Following previous celebratory experiences in the late quarter of the 19th century, such as Calderón's in 1881, a group of Spanish intellectuals proposed a huge and spectacular celebration on Quijote's tercentenary, a proposal adopted right away by Madrid politicians. In this article we explore the commemoration context from a nationalist, political and cultural point of view. More specifically we study how a historical nationality such as Galicia received and went through that proposal.
\end{abstract}

Keywords: Cervantes; Tercentenary; Quijote; Nationalism; Regionalism; Galicia; Galleguismo.

* Este trabajo ha sido financiado generosamente por SSHRC (Canadá). El título copia la aportación de Eloy Luis André a la celebración gallega del tricentenario.

** McGill University. jesus.perez@mcgill.ca / ORCID iD: https://orcid.org/0000-0001-79795915. 


\section{Cómo citar este artículo / Citation}

Pérez-Magallón, Jesús. 2020. «Galleguismo y quijotismo: a propósito del tricentenario del Quijote». Anales Cervantinos 52: 119-143, https://doi.org/10.3989/anacervantinos.2020.005.

En 1905 se publica en La Coruña El centenario del «Quijote» en Galicia. Estamos ante el documento más destacable que encarna la implicación de los círculos letrados gallegos en el recuerdo de los trescientos años de la aparición de la primera parte del Quijote. Como escribe Xoán Pastor Rodríguez Santamaría, «O Quixote uniu conservadores, liberais, rexionalistas e republicanos» $(2005,77)$, porque es cierto que todas esas adscripciones o tendencias se encuentran en el folleto de El centenario. Y sobre esa idea, la pregunta que se impone es: ¿acaso todos contemplan/utilizan/manipulan el Quijote de la misma manera? ¿Acaso el capital cultural de Cervantes y el Quijote, por aplicarles el conocido concepto de Pierre Bourdieu (1979, 3-6), tienen el mismo valor de uso para todas las corrientes políticas que coinciden en $\mathrm{El}$ centenario?

En las páginas que siguen, sobre la base de los estudios culturales, vamos a empezar revisitando la situación europea y española en que surgen algunos nacionalismos, para detenernos en Galicia. Seguiremos con el proyecto centralista de celebrar el tercer centenario de la aparición de la primera parte del Quijote y llegaremos a la conmemoración gallega, y en particular al folleto publicado por la Liga de Amigos de La Coruña. En concreto, analizaremos tres aspectos: la presencia de la lengua como factor diferencial, la raza y su relación con el Quijote, para acabar con las miradas que no muestran signos claros de galleguismo o son claramente españolistas. Cerraremos este artículo con unas breves conclusiones.

\section{UNA PRIMERA RECONSIDERACIÓN SOBRE EL NACIONALISMO Y SUS PROBLEMAS}

A mediados del siglo XIX un conjunto de factores desencadena la condensación de los sentimientos regionales, nacionales o nacionalistas en las naciones históricas de la periferia, de forma que se articulan las primeras manifestaciones de su especificidad: esos factores son los nacionalismos en otros países de Europa occidental, en gran medida estimulados por las guerras napoleónicas y la crisis concomitante del mapa geopolítico europeo, el cambio paradigmático político-cultural del Romanticismo y, en particular, su exaltación de los espíritus populares, de las naciones y de las lenguas y literaturas nacionales, todo ello como marco en el que las clases dominantes tratan de consolidar, ampliar o construir un mercado único para el mejor desarrollo de las fuerzas productivas, sin alterar las relaciones de producción que garantizan 
la acumulación de capital, y espacio para ejercicio de su poder y hegemonía, proceso este que acentuará las rivalidades intercapitalistas, el progreso del obrerismo internacionalista y conducirá a las dos guerras mundiales como han estudiado Linda Colley (1992) o David A. Bell (2003). En España la salida del absolutismo fernandino y la conflictiva construcción de un sistema democrático, la pérdida del imperio y la agitación nacionalista de las élites letradas periféricas les van a permitir a estas condensar sus primeras manifestaciones culturales en el Rexurdimento y la Renaixença, seguidas por un movimiento ideológico, político y social semejante pero no idéntico a nivel cultural en el País Vasco, un movimiento que Aizpuru llama renacimiento cultural vasquista propiciado por la abolición de los fueros y la reorganización de las fuerzas políticas y culturales $(2000,61)$.

Porque, en efecto, en el marco de un nacionalismo español centralista, inestabilizado por el peso del monarquismo reaccionario de los fernandinos -que se verá continuado por el carlismo una buena parte del siglo- y la debilidad vertebradora del liberalismo decimonónico en oposición al conservadurismo constitucionalista, circunstancia agravada por la pérdida masiva del imperio colonial y su incidencia sobre la vida económica de la metrópoli, esta contemplará el surgimiento de movimientos culturales y políticos en las naciones periféricas del estado. Específicamente, ahora nos interesa lo sucedido en Galicia, nación histórica que, como escribe Álvarez Junco, por una parte, «reúne todos los factores étnicos que para un planteamiento primordialista explicarían una movilización nacionalista» $(2016,252)$, y, sin embargo, por la otra, no va a ser escenario de la articulación de un potente movimiento nacionalista sino hasta la II República. Tierra de pueblos célticos, luego de los suevos y visigodos, muy poco afectada aparentemente por la llegada de los pueblos musulmanes a la península -aunque estudios genómicos recientes quieren demostrar lo contrario-, podría hablarse de una continuidad étnica que pocos territorios de Iberia podrían reclamar para sí.

Para contextualizar el tricentenario quijotesco, conviene empezar recordando brevemente el surgimiento y desarrollo del sentimiento diferencial gallego, que se sitúa claramente en lo que algunos autores han llamado el galleguismo pre-nacionalista. Para 1905, el movimiento que refleja un sentimiento específico y protonacionalista en Galicia parece mostrar varias caras: la del provincialismo gallego, encarnado en la Academia Literaria de Santiago de Compostela, vinculado al galleguismo liberal progresista y protagonizado por Antolín Faraldo, Neira de Mosquera o Martínez Padín; y la del regionalismo galleguista, «diversificándose ideológicamente e incorporando las aportaciones del Rexurdimento» (Núñez Seixas 2002, 5), al que se inscriben Manuel Martínez Murguía en el ala progresista-liberal y Alfredo Brañas en el ala conservadora, con una corriente minoritaria de federalismo republicano, dirigida por Aureliano J. Pereira y representada por Segundo Moreno Barcia, cuatro figuras que, según González Beramendi, «personifican las tres tendencias ideológicas que coexisten conflictivamente en el regionalismo gallego» $(1997,25)$. A todos ellos les seguirán más tarde, hacia 1916, las Irmandades dos Amigos da Fala 
con los hermanos Villar Ponte y otros, figuras cruciales ya en la constitución del nacionalismo gallego pues, según dice González Beramendi, «protagonizan la primera fase propiamente nacionalista del galleguismo político» $(1997,35)$. Fusi y Palafox sostienen una visión parecida, pues la creación de las Irmandades y la publicación en 1920 del ensayo Teoría do nacionalismo galego, de Vicente Risco, «marcaron el paso del galleguismo cultural y regionalista al galleguismo abiertamente nacionalista» $(1997,188)$. Esas dos corrientes del regionalismo gallego - la de Murguía y la de Brañas- se distanciarían rompiendo su unión en 1897. En este año, Manuel M. Murguía, con sus discípulos Salvador Golpe, Eugenio Carré, Manuel Lugrís y Galo Salinas, fundan la Liga Gallega de La Coruña, historicista, celtista, progresista y autónoma. En 1898, Alfredo Brañas funda por su parte en Santiago de Compostela la Liga Gallega de Santiago, tradicionalista, católica, carlista y autonómica. Como escribe González Beramendi, los años «entre el ocaso de la Solidaridad [Gallega] y 1916 son de oscurecimiento total del galleguismo político» $(1997,29)$. Aunque los sentimientos nacionalistas están ya ahí, el grupo que va a articular abiertamente un nacionalismo político gallego será la Organización Republicana Gallega (ORGA), fundada en 1929 por Santiago Casares Quiroga y a la que se sumarán Antón Villar Ponte y Luciano Peña Novo. De la ORGA saldrá el Partido Galleguista, formado por miembros decepcionados de la anterior y que tendrá un cierto protagonismo durante la II República, momento en que, según Núñez Seixas, el galleguismo «conoció una fase de acelerada expansión social y política» $(2002,2)$.

La formulación de Manuel Martínez Murguía en su obra El regionalismo gallego parece muy clarificadora de las aspiraciones y de las limitaciones del regionalismo. Así, en el «Prólogo» a la obra escribe Waldo Álvarez Insua, que según González Beramendi $(1997,17)$ había participado en la redacción del Diario de Santiago entre 1872 y 1878:

¿Qué mucho, pues, que Galicia, antiguo reino suevo, nacionalidad legítima e independiente, con todos los elementos necesarios para desarrollar sus aptitudes y cumplir sus fines históricos, proclame con noble ardimiento el derecho a reconstruir su vida regional, reparando al mismo tiempo los desperfectos económicos que una administración desastrosa ha originado en cuatrocientos años de gobierno? (Martínez Murguía 1889, Iv).

La construcción del discurso nacionalista, o más específicamente el regionalista gallego, incluye, a semejanza de otros movimientos de la misma índole, como uno de sus puntos clave a fin de suscitar el apego psicológico necesario entre sus seguidores y, a medio plazo, sectores importantes de la población, la posición de la lengua y la cultura, factores fundamentales al abordar el tema de la identidad regional o nacional. Y, junto a ellos, en la creación de la identidad de cada nación, y también de la gallega, el papel de la raza ocupa un espacio indiscutible, más concretamente la especificidad racial de Galicia que se encontraría en las raíces célticas, aunque los partidos 
nacionalistas y los nacionalismos hayan intentado borrar este componente de su programa fundacional.

Siguiendo los pasos de autores como José Verea y Aguiar -que publicó en 1838 una Historia de Galicia donde traía el celtismo desde autores franceses interpretados por Juan Francisco Masdeu- o Benito Vicetto, que en su novelesca Historia de Galicia (1865-1873, en 7 volúmenes) se había inventado muy ficticiamente una raza celta y un carácter nacional gallego, pero también recogiendo los escritos de autores como Amédée Thierry o de William $\mathrm{F}$. Edwards (Piguet 2000), Manuel M. Murguía establece en el ámbito teórico del galleguismo -desde su «Discurso preliminar» a la Historia de Galicia, hasta el Discurso del Tui pasando por El regionalismo gallego- un pasado de Galicia en clave racial, y «sienta las bases de lo que será la definición canónica de nación gallega, a pesar de las vacilaciones terminológicas» (González Beramendi 1997, 22). Para Murguía, en efecto, tal y como lo describe González Beramendi,

la raza celta, el tronco ario y reforzada después por el aporte suevo, se asentó en el territorio galaico, conservó casi intacta su pureza hasta hoy (cosa que niega a los demás pueblos peninsulares, según él más o menos contaminados todos con sangre semito-africana) y, en íntima comunión con una tierra de caracteres únicos, generó a lo largo de la historia un Volkgeist propio $(1997,22-23)$,

pues a pesar de las inevitables e indiscutibles hibridaciones entre los habitantes primitivos, los romanos, los suevos y visigodos, Murguía se aferra a la pureza de la raza celta de Galicia. Una raza cuyos rasgos definitorios serían amor a la tierra, instinto de posesión territorial, religiosidad, inteligencia, lirismo, resistencia y ausencia de agresividad conquistadora. Como escribe Álvarez Junco, lo novedoso en el giro nacionalista de Murguía es que

los sujetos de la historia eran, para él, las "razas", con sus "esencias físicas y morales" fijadas de forma inmutable por la providencia. Y la raza originaria del territorio gallego no era la española. Lo era la celta, una "nacionalidad" caracterizada pola valentía, o odio a toda dominación allea, a relixiosidade e o amor a térra $(2016,262)$.

Abundando en el carácter rupturista del enfoque de Murguía, Maíz Suárez sostiene que

el verdadero punto de ruptura, más que de continuidad, desde este punto de vista historiográfico, inaugurador de la historia nacionalista gallega, debe situarse en la Historia de Galicia (1865) de Martínez Murguía, donde, en superación del horizonte provincialista [...] se sientan las bases de la identidad nacional gallega y sus mitos fundadores centrales $(1996,41)$.

Más específicamente, según el mismo autor, la aportación clave de Murguía 
sería la elaboración del marco interpretativo fundador del nacionalismo gallego sobre el mito céltico de los orígenes («la base étnica de Galicia es céltica»), destinado a generar, más allá de su inverosimilitud histórica, un efecto generador de evidencia nacionalitaria que desempeña una plural y compleja funcionalidad político-ideológica como «articulación simbólica» (Maíz Suárez 1996, 43).

\section{El TRICENTENARIO DEL QUIJOTE: UNA EMPRESA NACIONAL}

En 1903 -cuando «el galleguismo sigue circunscrito mayormente a las actividades culturales y periodísticas» (Núñez Seixas 2002, 7) o «al ámbito teórico-cultural-periodístico» (González Beramendi 1997, 29)- Mariano de Cavia llamó desde Madrid el 2 de diciembre, en las páginas de El Imparcial, el periódico liberal más importante del momento, a la celebración del tricentenario de la publicación del Quijote que, lógicamente, tendría que tener lugar dos años después. Como escribe Xavier Andreu Miralles, «en España se podía detectar desde las últimas décadas del siglo XIX y en las primeras del XX una fiebre conmemorativa acorde con lo que ocurría entonces en el resto del continente» $(2016,174)$. Eric Storm rastreó sagazmente el marco intelectual en que surgió la propuesta verbalizada por Cavia: la redacción de la revista Vida Nueva, publicada en 1898, donde colaboraron letrados liberales tan significados como Jacinto Octavio Picón, Vicente Blasco Ibáñez, José Ortega Munilla o José Jurado de la Parra. Como sintetiza Storm, la orientación de la revista era «fundamentalmente social-liberal y de nacionalismo moderado» (2008, 7), y abogó durante su existencia por la regeneración política, económica y cultural de España. En sus páginas ya en octubre y noviembre de 1898 Pérez Galdós proponía -aunque el artículo, según Peter Bush $(1980,8)$ se había publicado en La Nación treinta años antes-, recuperar la memoria y significancia de Cervantes pues en él se condensaba el brillante pasado cultural de España, albergue del único orgullo nacional duradero, en oposición al Desastre (con mayúsculas), o sea, a la pérdida de los últimos territorios coloniales.

Siguiendo el artículo de Cavia y las intervenciones de Ortega Munilla y Picón en el Congreso de los Diputados, el gobierno español, presidido por el conservador Antonio Maura y Montaner, hizo publicar en la Gaceta del 2 de enero de 1904 el real decreto en el que la celebración del centenario se justificaba porque patentizaba

que la santa unidad a quien el amor llama patria, no solo funde la diversidad de pueblos, territorios, intereses y anhelos de un día, sino también el patrimonio espiritual atesorado por las generaciones que pasaron y los alientos vivificadores con que se han de realizar los providenciales destinos colectivos (Sawa y Becerra 1905, 103). 
Por debajo de la retórica decimonónica que muestra, y de la Junta que se forma, lo que queda claro es el objetivo político y cultural del partido en el gobierno: manipular el capital cultural simbólico de Cervantes y el Quijote para reforzar la unidad nacional desde la perspectiva centralista, que tiene como soporte a Castilla, y conservadora, arrebatándole la iniciativa a los liberales y apropiándose de los beneficios políticos que pudiera producir la celebración, además de preparar anímica y psicológicamente a la nación para algunas empresas más que problemáticas que se encontraban en la agenda del poder, como la cercana intervención en el norte de África. Storm resume los objetivos del centenario como algo «pensado sin duda para estimular la conciencia nacional de la población y promover la modernización del país [...] ser un importante paso hacia un renacimiento nacional» $(2008,7)$, visión que sincretiza enfoques y programas divergentes. Y si la exaltación de Cervantes a monumento nacional de toda España se consolidó en 1835 con la erección de su estatua ante el Congreso de los Diputados (Pérez Magallón 2015, 13 31), ahora las conmemoraciones masivas formaban parte de otro proyecto: el de tratar de recomponer un espíritu nacional asediado por la pérdida de las últimas colonias y el auge de los movimientos nacionalistas periféricos en la península, el de regenerar una nación perjudicada por los acontecimientos y necesitada de un nuevo empuje que profundizase la modernización del país y la nacionalización de la nación (Archilés 2007, Miralles 2016), valga la redundancia.

En efecto, ver la conmemoración -el tricentenario del Quijote- como memoria cristalizada le otorga un valor imaginario y afectivo que trasciende incluso la manipulación política partidista que intentó imponerle el gobierno conservador del momento. En realidad, poniendo en relación los estudios de autores como John R. Gillis (1994) y Anthony D. Smith (1991), podemos señalar que las conmemoraciones desempeñan un papel clave en la construcción de la nación y la identidad nacional, ya que permite a los habitantes de un país reconocerse en una imagen de la nación aludida o reforzada por la celebración y la ceremonia, en la celebración de una parte de la memoria que quiere presentarse como común y compartida. Como escribe Moreno Luzón, «El estudio de las conmemoraciones abre pues una ventana al análisis de las ideologías y los movimientos nacionalistas y de las identidades nacionales en un momento dado, y también al de las vivencias de la nación por parte de la gente» $(2007,26)$. Sin embargo, lo que se constata en el proceso de reivindicación, enfrentamiento y lucha por la hegemonía es precisamente el movimiento de los diversos sectores por apropiarse la celebración y de esa manera marcar con la firma de un partido o una corriente política el signo del gesto social y ritual que es la conmemoración.

Las reacciones a la propuesta de Cavia, sin embargo, fueron múltiples y encontradas por diversas razones. Entre ellas se contaba con la inevitable confrontación entre las visiones de las diferentes corrientes políticas españolas. Pero una de esas razones fue, además, la perspectiva político-territorial y, como consecuencia, regional o nacional con la que contemplar y juzgar la 
propuesta. Aunque más adelante y en otro momento y lugar nos acercaremos a otros territorios nacionales -País Vasco y Cataluña-, baste señalar que algunos grupos y personalidades nacionalistas se opusieron frontalmente a incluir a Cervantes y su Quijote en el patrimonio cultural de sus respectivas naciones, en tanto otras corrientes e individuos, desde todas las regiones de la península, creyeron que se abría una buena oportunidad para reflexionar sobre el Quijote, claro, pero también sobre las relaciones entre las diversas naciones y comunidades del Estado español. A ellos se añadieron quienes defendieron una posición españolista sin importar el lugar en que se encontrasen.

Lo que destaca en la propuesta de Mariano de Cavia es, por encima de todo, y más allá del alcance previsible entre los círculos letrados de la península, una aspiración de participación global de la sociedad civil o, por decirlo de otra manera, un deseo de llegar a celebrar a Cervantes y el Quijote con una fiesta de dimensiones barrocas, en cierto sentido semejante e incluso más ambiciosa que la que había tenido lugar en 1881 con el centenario de la muerte de Calderón (Álvarez Junco 2001, 449). Podemos decir que lo más destacable es la ambición de su proyecto, que va mucho más allá de la típica y tópica celebración restringida al ámbito de la cultura, pues, dijo Cavia, había que hacer «la más luminosa y esplendorosa fiesta que jamás ha celebrado pueblo alguno en honor de la mejor gloria de su raza, de su habla y de su alma nacional» (Sawa y Becerra 1905, 93). A esas palabras cargadas de simbolismo cultural y político, Eric Storm añade la siguiente apostilla: «Desafortunadamente para el autor, esto resultó en gran parte un ensueño» $(2008,5)$. Lo cierto es que la celebración del tricentenario, surgida en el centro del Estado, donde provocó las tensiones y conflictos que hemos señalado someramente, solo cobró verdadera realidad a nivel local, es decir, en el terreno en el que los procesos de nacionalización se mostraban con más claridad y tal vez mayor eficacia pues, como afirma Quiroga: «La nación llega a los individuos mediada por las instituciones locales y ese proceso de intermediación la hace más cercana a los ciudadanos» $(2013,22-23)$. Lo local, en efecto, no solo funciona como intermediario entre lo nacional y lo individual, sino que «se convierte en el espacio generador de identidad nacional» (Quiroga 2013, 23).

\section{GALICIA EN EL TRICENTENARIO DEL QUIJOTE}

Porque, en efecto, para conmemorar la publicación de la primera parte de Don Quijote, la Universidad y el Instituto de Santiago de Compostela organizaron el 7 de mayo de 1905 una celebración ciudadana cuyo programa completo se anunciaba en El Correo de Galicia del 5 de ese mes, refiriéndose a los «solemnes actos académicos» (Sawa y Becerra 1905, 418), en los que leyeron discursos Juan Barcia Caballero, José María Ruano y Armando Cotarelo, continuados el 9 de mayo en que se celebró la procesión cívica, «con 
asistencia de los niños de las escuelas públicas, alumnos de la Escuela de Artes e Industrias, Normal de Maestros, Instituto, Farmacia, Filosofía y Letras, Medicina, Ciencias y Derecho» (Sawa y Becerra 1905, 418), además de un carruaje con el gallardete de Lepanto, propiedad del cabildo de Santiago, que depositó coronas ante el busto de Cervantes. Ferrol localizó en el Ateneo la velada literaria en que tomaron parte Andrés Avelino Comerma, Alfredo de la Iglesia, Emiliano Balás, Aurelio Ribalta, Federico Landrove y Rodrigo Sanz. El Casino de Lugo celebró, asimismo, una fiesta literaria en la que destacó la participación de Gerardo Álvarez Limeses, en tanto el Instituto General y Técnico de la misma ciudad organizaba una velada literaria en la que hablaron Daniel Fraga, Feliciano González y varios alumnos; y la Escuela graduada de esa ciudad tuvo también una fiesta en la que, junto al discurso de su director, Victoriano Tuñón, leyeron poesías y fragmentos del Quijote algunos alumnos. Orense, Pontevedra y Vigo se sumaron generosa y numerosamente a la celebración nacional.

No deja de ser sorprendente que el Archivo Histórico de la Universidad de Santiago no haya conservado ningún expediente específicamente consagrado a la celebración del tricentenario, cosa que sí ha hecho el Arquivo do Concello de A Coruña, donde, al consultar el legajo C-977 (010), «Expediente sobre conmemoración del tercer Centenario de la publicación del Quijote» ${ }^{1}$, sin paginar - por lo que debo dar las gracias a la técnica media de archivo María Cristina Sánchez Quintero, amable, cuidadosa y generosa-, hemos podido rastrear y seguir con multitud de detalles lo que fue la intervención directa de las instituciones en dicha conmemoración. En el expediente de Coruña se cartografían con claridad burocrática los diferentes escalones de la jerarquía que intervinieron en la celebración del tricentenario. Desde el oficio del ministro al del gobernador civil para llegar al alcalde y sus numerosos besalamanos a las personas e instituciones ya directamente implicadas en el buen éxito de la festividad. Vamos, pues, a ver en qué forma concreta se ejecutó la decisión del Ejecutivo respecto a la conmemoración. El primer documento del expediente mencionado es una copia del telegrama que el ministro de Instrucción Pública y Bellas Artes, a la sazón Juan de la Cierva y Peñafiel -quien, para las fechas de la conmemoración, habría dejado el ministerio para cedérselo a Carlos M. ${ }^{a}$ Cortezo y Prieto- bajo la presidencia de Raimundo Fernández Villaverde, del Partido Conservador, dirige a los gobernadores de las cuatro provincias gallegas recordándoles que se han fijado los días 7, 8 y 9 de mayo para celebrar el centenario: «Agradecería mucho el Gobierno que convoque reuniones y excite a todos los centros para ello y le aconsejo procure en todas las poblaciones donde sea posible que con este motivo se inicien suscripciones para construir escuelas». El 12 de febrero de 1905 el gobernador Luis Soler Casajuana (1852-1917) -del Partido LiberalConservador, gobernador en diversas provincias, director de la revista Espa-

1. Arquivo do Concello de A Coruña. 1905. «Expediente sobre conmemoración del tercer Centenario de la publicación del Quijote», legajo C-977 (010). 
$\tilde{n} a-$ envía un oficio a los alcaldes con la copia del telegrama e instándolos a organizar «las fiestas para solemnizar» el tricentenario, así como el propósito del ministro de que la Comisión organizadora tenga presente la suscripción «para la edificación de escuelas». La constitución de la Comisión es objeto del intercambio de oficios entre el gobernador civil y el alcalde de La Coruña, Francisco Mariño García, que fallecería en noviembre de 1905, siendo presidente de la misma, en particular sobre el representante del Ejército, que sería el teniente coronel de Artillería José Pita.

El 15 de febrero Luis Soler, el gobernador, envía un besalamano al alcalde para que convoque «a los corresponsales de los periódicos de Madrid a la reunión que mañana ha de celebrar la Comisión», como prueba de consideración y por sus patrióticos servicios. Por si acaso al alcalde se le olvidaba la idea, le envía otro besalamano el mismo día conminándolo a que invite también a la Revista Gallega, que no es diario sino semanario. Se conserva la lista de personas invitadas a la reunión, que luego publicó en portada el 17 de febrero el periódico El Noroeste, entre quienes se encontraban representantes de la Asociación de Bellas Artes, la Reunión de Artesanos, el SportingClub, la Diputación Provincial y otras instituciones, así como todos los periódicos y el semanario citado. En la noticia se mencionan las dos tendencias en que se había dividido la Comisión: una que proponía una celebración puramente académica y la otra que era partidaria de celebrar «con festejos populares, organizando una cabalgata que representase escenas del Quijote», tendencias que el alcalde supo unificar haciéndolas compatibles. Todas las asociaciones apoyaron la idea y cada una propuso su forma concreta de participar, algunas pusieron la cuestión económica por delante, el alcalde publicaría un bando rogando al vecindario que iluminara sus casas, el Ejército y la Marina contribuirían con sus recursos y la Comisión encargó a uno de sus individuos para que organizara un acto fúnebre por el eterno descanso de Cervantes. Muy de pies en el suelo, «los alumnos del Instituto general y técnico piensan reunirse en fraternal banquete para conmemorar el centenario del Quijote. Celebrárase el banquete en el Hotel de Francia». Terra Gallega, diario republicano, además de la información general, detalló que el Ayuntamiento y la Diputación Provincial «contribuirán con una suma que acaso no baje de 5.000 pesetas». Las solicitudes a los ayuntamientos por parte de corales y otras asociaciones culturales fueron muy frecuentes, y recibieron en general el apoyo decidido de las instituciones. El 25 de abril el alcalde envía besalamanos a los responsables de las instituciones académicas y religiosas pidiéndoles le comuniquen «las solemnidades que el clero de esta capital dedica a conmemorar el centenario del Quijote a fin de poder formar el correspondiente programa general» con la intención de «ponerlo en conocimiento del Gobierno de S. M.». Ante este requerimiento, los interesados responden con oficios en que detallan las actividades que planifican.

Así, Segundo Moreno Barcia, director de la Escuela Superior de Comercio, anuncia el 26 de abril una «solemne sesión literaria» para el 8 de mayo; José Pérez Ballesteros, director del Instituto General y Técnico de La Coruña, 
expone un plan preciso con 5 actos, que incluyen el reparto de ejemplares del Quijote, y así sucesivamente. Excepcionalmente, el marqués de San Martín, presidente de la Academia Provincial de Bellas Artes de La Coruña, se excusa el 29 de abril e informa de que «esta corporación no puede tomar parte, como se había propuesto, con ninguna solemnidad [...] por impedírselo varias dificultades que impiden la realización de la velada proyectada». El coronel Jacinto Martínez Dabán, del Regimiento de Infantería Isabel la Católica número 54, en un besalamano informa al alcalde que «accede gustosísimo a que la banda de música de este Regimiento concurra a amenizar los paseos de los días 7, 8 y 9 próximos». La Escuela Gratuita de Ciegos y Niños Pobres imprimió un programa fechado el 1 de mayo que incluía Himno a Cervantes, Breve narración o noticias sobre la vida y obras de Cervantes, Sinfonía por el cuarteto de la Escuela, Poesía a Cervantes declamada por el niño de seis años de edad Recaredo García e imprecación a Sancho Panza, declamada por el alumno Juan Rivero, Ovillejos de otros alumnos, La vuelta de Escarramán, juguete cómico-lírico en prosa y verso, coro y música. Tierra Gallega publica en la portada del 4 de mayo los diferentes programas de actos planificados. Varios oficios de los directores de centros o presidentes de asociaciones invitan al alcalde a las sesiones literarias o jornadas festivas que tendrían lugar entre el 7 y el 9 de mayo. El Ayuntamiento procedió a la adquisición de algunos ejemplares del Quijote siendo repartidos 112 a los diversos centros para su entrega a los estudiantes. Un conjunto de besalamanos agradece a todos los responsables por su entrega y el buen desarrollo de la conmemoración. De esa manera, el ciclo se cierra y el gesto burocrático, cultural y político llega a su fin.

Entre esas celebraciones gallegas, merece la pena detenernos en la intervención de la Liga de Amigos de La Coruña, constituida a iniciativa de Francisco Javier Fariña y establecida el 29 de septiembre de 1903, con José María Riguera Montero como presidente y Luis Cornide Quiroga como secretario, que fue receptiva y favorable, asumiendo la responsabilidad de recordar el tricentenario de una manera visible y significativa. A los oficios del alcalde de Coruña invitándolo (o conminándolo) a participar en la celebración, Narciso Túñez, presidente a la sazón de la Liga de Amigos, respondía el 31 de marzo de 1905 anunciando que «costeará un lujoso número de 30 o más páginas, ilustrado con láminas en color y al fotograbado, editado en La Coruña y con textos literarios y dibujos de los más notables escritores y artistas de la región gallega que han ofrecido patrióticamente su concurso», y preguntándole de paso al alcalde el número de suscripciones con las que apoyaría esa publicación. Aunque no tenemos la respuesta del alcalde, sabemos que ese proyecto de la Liga siguió adelante. Sin embargo, no hay duda de que esa no fue la actitud de todo el sector regionalista. En efecto, en la misma publicación de El centenario del «Quijote» en Galicia, en el artículo «Justicia y gratitud», el presidente de la Liga de Amigos, Narciso Túñez, informa a sus lectores de que, tras publicarse en los diarios locales el acuerdo de la Junta Directiva de la Liga sobre la edición del folleto homenaje, recibió una carta 
en la que un gallego celoso -que firmaba como Un gallego amante de la justicia- advertía:

Hará mal la Liga de Amigos de La Coruña tributando el menor homenaje a Cervantes, a quien nada debe Galicia, como no sean injurias. Que le celebren castellanos, aragoneses o catalanes es natural, puesto que él ensalzó esas tierras, pero los gallegos no debemos tomar parte en la apoteosis del que tan injusto fue con Galicia $(1905,31)$.

La razón de este gallego que se opone a celebrar la publicación del Quijote no es otra que su lectura de las «injurias» cervantinas de Galicia. Túñez asume en ese contexto la defensa de la decisión tomada por la Liga de Amigos. La justificación del presidente no cae en un patriotismo español, sino que pone el énfasis en el desconocimiento de Cervantes sobre la realidad gallega, pero mucho más significativo es que recurra a Emilio Castelar -calificado por Gómez de la Serna como «un gran cursi»- y su prólogo a la colección de poesías de Rosalía de Castro, Follas novas, para señalar cómo ese desconocimiento de Galicia continúa hasta el tiempo presente. En pocas palabras, el recurso retórico de Túñez no es otro que disculpar a Cervantes -y a todos los españoles por extensión- de una ignorancia que se explica por las circunstancias históricas y temporales de cada autor. Porque, parece ser, el problema clave de las relaciones entre Galicia y España -o el resto del mundo, para lo que eso vale- es el desconocimiento que ese mundo tiene de la zona noroccidental de la península ibérica y, podríamos decir también por extensión, del mundo céltico en la península. En Galicia -dejemos de lado los mitos- hay un mundo que simplemente es desconocido. Y poco importa si el ignorante es un español o un inglés, un andaluz o un alemán.

\section{LA LENGUA GALLEGA Y EL GALLEGUISMO}

La significación de la lengua gallega, como ya apuntamos, fue uno de los puntos clave del regionalismo, y basta con revisitar el libro de Murguía en el que incluso especula con la posibilidad de que el gallego se hubiera podido convertir en la lengua del reino de León, «si en vez de unirse con Castilla en el siglo XIII lo hubiese hecho con Portugal y, en fin, si después de esto, la monarquía castellana hubiese entrado a formar parte del Estado portugués» $(1889,12$, n. 2). Para concluir que «en verdad nada se perdería en ello. Camoens vale bien Cervantes» $(1889,12$, n. 2$)$, idea que se debe tener presente para el tipo de indagación que llevo a cabo, porque, puestos a ensalzar iconos culturales, tanto vale Isabel como Fernando. Siguiendo la lógica del regionalismo de Murguía, Aurelio Ribalta Copete, implicado intensamente en la creación de las Irmandades da Fala bien entrado el siglo XX, haría en 1915 un llamamiento desde su revista para defender la lengua gallega, idea que cobraría una nueva dimensión en Antón Vilar Ponte, quien en enero del año 
siguiente inició en La Voz de Galicia una campaña para constituir la Irmandade dos Amigos da Fala. Porque Ribalta Copete (1864-1940), galleguista nacido en Ferrol e instalado en Madrid, donde funda la revista Estudios Gallegos con Rodrigo Sanza y otros, siendo o llegando a ser secretario del marqués de Figueroa, Juan Armada y Losada, diputado conservador por La Coruña y ministro de Gracia y Justicia, participa en la celebración del tricentenario cervantino con un artículo titulado «De cómo debemos leer los gallegos el Quijote», donde el énfasis cae sobre tres puntos centrales: el papel de la lengua, la importancia de esta para la juventud y la necesidad de fomentarla a través de justas literarias o juegos florales, según el modelo catalán de los jocs florals, práctica que también se impuso en el País Vasco por influencia de Antoine d'Abbadie y Jean Duvoisin.

En efecto, su colaboración a este folleto sobresale por su preocupación por la juventud gallega, pues son «nuestros mozos» (1905, 10), dice, quienes tienen que leer el Quijote, y no solo «los que van para letrados» $(1905,10)$, sino todos aquellos que estudian para llegar a ser «útiles a su país» (1905, 10). Ribalta toma como referencia la lengua castellana de su tiempo, que sufre una decadencia y deformación que «el mismo Cervantes no la conociera» $(1905,10)$. Y si el castellano actual de 1905 -inutilizable en una empresa de reanimación cultural- está degradado, la lengua de Cervantes, por su aire anticuado y arcaico, parecería como una lengua muerta e incomprensible. En una alusión sutil a la pérdida de las últimas colonias, Ribalta se hace eco de las palabras de Antonio de Nebrija en la dedicatoria de su Gramática a la reina Isabel «que siempre fue la lengua compañera del imperio», para explicar «que ande acabada y en desuso la solemne y alterosa manera de ser que antaño tuvo su lengua, desmedrada como la ventura del pueblo que la pronuncia» $(1905,11)$. En otros términos, perdido el imperio, perdida la lengua. Pero Ribalta precisa todavía más esa pérdida del imperio, porque lo que constata es la pérdida «del dominio de fuera y el predominio de dentro de España» $(1905,11)$, en alusión clara a la aparición de otros nacionalismos rivales del castellano. El Quijote por tanto se convierte en el cuerpo extendido donde se denuncia la hegemonía del castellano en Galicia y, como consecuencia, de la defensa y exaltación del gallego. Porque, si no puede ni debe emplearse la lengua de Cervantes, la juventud gallega encontrará el sustituto inmejorable «en el cultivo gramatical de su propio idioma, el gallego» $(1905,11)$, al que se dedican filólogos «extranjeros, por supuesto» $(1905,11)$, dice con ironía, y otros del país, incluyéndose a sí mismo en esa empresa.

En ese contexto argumentativo Ribalta recuerda el capítulo XVI de la segunda parte del Quijote donde Cervantes defiende, según el autor, «que cada cual debe de hablar en la lengua que ha mamado con la leche», lamentando, con Saco y Arce, autor de la primera gramática gallega, «que únicamente en las poblaciones galaicas se desdeña su cultivo» $(1905,11)$. Y, seguidamente, llama la atención sobre la influencia que la lengua gallega tuvo sobre la prosa cervantina y la labor pionera de Armando Cotarelo Valledor, catedrático de Literatura Española en la Universidad de Santiago, al incorporar la lengua 
gallega en su programa y organizar unas justas literarias (equivalentes a los jocs florals de Cataluña) con temas en gallego. Para Ribalta, de la esterilidad cultural en gallego solo se puede salir «como salió la cultura catalana, en alas del idioma propio» $(1905,11)$.

La reivindicación y recuperación de la lengua gallega, esa pieza crucial para el regionalismo y los nacionalismos en general, impone afrontar un problema de carácter sociológico y cultural: la actitud global de rechazo de la lengua propia por la clase media de Galicia, que priva a sus hijos «del uso del gallego por creerlo patente de ordinariez, aun bien hablado» $(1905,11)$. Entramos aquí en un asunto de modas y prestigios, porque Ribalta juzga que esta creencia «acredita de cursi a la clase media de Galicia» $(1905,11)$. ¿Por qué es cursi esa clase media? Porque, en su afán por presentarse como un grupo refinado y a la última, ha decidido menospreciar el gallego como lengua de los aldeanos y el pueblo bajo. La cursilería -estudiada en profundidad por Noël Valis (2002) para España- que, como concepto generado y acotado por la élite, inscribe un desprecio solo propio de las clases altas, conduce inexorablemente a la burla y censura de lo ridículo que se agazapa detrás de lo que quisiera ser exquisito. Así, desde la superioridad intelectual, cultural y política del letrado, la clase media es cursi porque, en su desprecio del lenguaje regional/nacional, menosprecia al pueblo y a la sociedad humilde, frente a la que Cervantes ofrece un modelo opuesto, pues en su Quijote alberga los lenguajes de todas las clases sociales. El cierre del artículo manifiesta sin ambages el posicionamiento de Ribalta: la lectura que los gallegos deben hacer del Quijote se resume en «iComparemos lo nuestro con lo suyo!» $(1905,12)$.

En esa misma lógica se ubican Eugenio Carré Aldao, que llegaría a ser secretario de la Real Academia Galega y director de A Nosa Terra, y Manuel Lugrís Freire, otro letrado que sería presidente de la Real Academia Galega. Ambos pueden incluirse entre los regionalistas debido a su fervorosa y clara militancia a favor de la lengua gallega. El primero, Carré Aldao, en «Cervantes, rexionalista», empieza recordando cómo de Cervantes se ha dicho todo, o casi, por lo que no tiene ningún inconveniente en hacerlo también rexionalista. Y para ello le basta con copiar las palabras del propio Cervantes en el capítulo XVI de la segunda parte que citamos antes, reivindicación con fervor mediante su clara, breve y concisa defensa de la lengua gallega y de la afirmación cervantina a favor de las lenguas vernáculas. El trabajo termina con una pregunta reveladora: «E agora, ¿qué dirán certos desleigados gallegos?» $(1905,17)$, es decir, una pregunta que pone el acento en la división social en torno a la lengua nacional, ya que esos «descuidados» aparecieron identificados en el trabajo de Ribalta. El enfoque de Lugrís Freire es algo más abierto, pues no se limita a una firme defensa del gallego, sino a una exaltación del bilingüismo. Así, hablando de Cervantes señala sus orígenes gallegos, pero no a la manera erudita y algo farragosa de otros letrados, sino para ponerlo en relación con Camoens, «los dos escritores más egregios del siglo XVI», pues los dos hombres, «los dos genios que llenaron con sus nombres la literatura de Castilla y Lusitania [...] eran oriundos de Galicia». En consecuencia, 
«los gallegos son, como los franceses meridionales, hombres superiores porque hablan dos lenguas» $(1905,28)$. Y en el cierre un deseo: la abolición del analfabetismo y la preservación de esas dos lenguas.

En el año de 1916, el 6 de enero más exactamente, el director de la Real Academia Española, el mismo Antonio Maura y Montaner que había convocado la celebración del tricentenario del Quijote, manda un escrito al ministro de Instrucción Pública para que se adopten medidas en defensa de la lengua y de respeto a la ley sobre el uso de la lengua española en todos los territorios del país. Su carta es publicada el 1 de febrero del mismo año en el diario $A B C$ bajo el título «La Academia y el idioma castellano», donde señala en su justificación que «ahora parece ponerse en duda por algunos la supremacía y predominio» del español. Afirma ahí Maura:

Idiomas o dialectos que se hablan en la intimidad del hogar o en las relaciones individuales, y que toman forma artística en literaturas regionales, son respetables, y la Academia los respeta y estima, porque el conjunto de las manifestaciones de la vida española forma la grandeza de la Patria; pero el verbo de esta como nación una e intangible es el castellano.

Aurelio Ribalta le respondió ese mismo mes de febrero desde las páginas de Estudios Gallegos en carta dirigida también al ministro de Instrucción Pública en la que exponía, en nueve puntos, una visión crítica de las palabras de Maura, una defensa de las lenguas no castellanas, un rechazo de la política represiva que el director de la Real Academia Española quería imponer y, sobre todo, un alegato de la necesidad de enseñar en las escuelas el idioma de Galicia. Para esas fechas, Antón Villar Ponte escribe el 8 de enero en esa revista: «Nos redimirá la escuela, o no nos redimirá nadie». Y Ribalta sostenía, en el editorial de enero de 1916 de Estudios Gallegos:

\footnotetext{
No podemos seguir viviendo sin la galleguización de nuestra intelectualidad y de nuestra finanza, a no ser que nos resignemos a seguir siendo eternamente esclavos de nuestros actuales dominadores: los políticos, que son, en el fondo, los principales interesados en nuestro atraso.
}

\section{Cuestiones de la RAZA Gallega}

Eloy Luis André (1876-1935), psicólogo, filósofo e incluso economista aficionado, desarrolla en "Galleguismo y quijotismo» una visión original de la sociedad gallega y de su relación con España. Este es, probablemente, el trabajo que «hoxe [...] máis interesa do folleto» (Rodríguez Santamaría 2005, 79). Estamos ante la aportación más significativa de El centenario, sin la menor duda. Y lo es porque el autor confronta sin reparos el quijotismo en su relación con la raza, puesto que don Quijote es «un vástago típico» (1905, 13) de la raza y, de manera concomitante, del espíritu nacional, que es otra 
manera de aludir a la identidad. Luis André arranca con una censura directa a la celebración, pues la Real Academia Española, «al honrar fúnebremente a Cervantes, se propone enterrar el quijotismo, que es sublimación de realidades y condensación de sueños» $(1905,13)$. Establece así una concepción del quijotismo que le va a servir de referencia para el resto del artículo. Y la siguiente pregunta que se hace el autor tiene que ver con la Región -Galicia- y su espíritu: «En vano ahondo por ver matices de mentalidad pletórica de ilusiones, embriagada, por sugestión, con grandezas» $(1905,13)$. Entonces la cuestión es saber si en Galicia también se ha enterrado a don Quijote, pero su constatación es más radical todavía, porque la realidad es que el alma de don Quijote nunca arraigó en el alma gallega, «Jamás, jamás» (1905, 13). La deducción automática es que el espíritu gallego, su identidad, nada tiene que ver con la de la raza española.

Busquemos la entraña del quijotismo en la raza, dice Luis André, pero el verdadero interrogante se abre en ese momento: «¿Puede injertarse el alma de don Quijote, llena de ilusión de grandezas, seriamente enloquecida, en nuestra alma gallega, que en basamento de vulpejería está afirmada?» $(1905,13)$. La palabra en cursiva, que no aparece en el DRAE, deriva de vulpes, zorro, nombre femenino en latín. Porque el alma gallega es el campo en que se muestra la tensión entre el lobo y el zorro, «la fuerza brutal del poder y la fuerza hábil de la astucia son los tipos eternos de nuestro espíritu regional» (1905, 13). En realidad, sin embargo, Luis André no habla aquí del pueblo gallego como una unidad, sino que se refiere claramente a unos sectores sociales muy precisos. En el «Prólogo» a Galleguismo se comprueba que estas características aluden a «los amos», para quienes «la fuerza brutal o la astucia -la del lobo y la del zorro- aplasta, dislacera, amedrenta, engaña y domina» $(1931,12)$. Por lo tanto, no es en Castilla donde hay que buscar el alma madre del espíritu gallego, sino en el norte. «Emparentamos espiritualmente más con la Galia que con Castilla» $(1905,13)$, dice el autor. Del mismo modo que Valentí Almirall contemplaba la identidad catalana más próxima a la inglesa que a la castellana, Luis André ve la identidad gallega más cercana a la francesa, en particular a la de Picardía, Normandía, Bretaña y la Île-de-France.

Tratando de acercarse a ese espíritu gallego, Luis André acude a uno de los tópicos del cervantismo anterior, y lo ve como el triunfo de la filosofía brutal y bonachona de los Sanchos, pues en Galicia «prepondera el practicismo astuto, el vulpinismo solapado, la insinuación, la suspicacia, el recelo» (1905, 13), valores que lógicamente se asocian al lobo y el zorro, porque es un pueblo «en acecho de felicidad, de felicidad pescada y no adquirida a pulso, pueblo de lobos y de zorros, no de Sanchos y Quijotes» $(1905,13)$. En otras palabras, la percepción que conceptualiza Luis André es -consignando los hechos- un alma gallega que «no lleva dentro de sí un ideal, un ideal de auto redención, un ideal de rebeldía. No tiene espíritu aventurero en su propio espíritu» $(1905,13)$. En ese contexto, devalúa el sentido de los peregrinajes de gallegos, pues, en comparación, don Quijote, cabalgando por las tierras manchegas, «es más aventurero que el emigrante de nuestros campos o de 
nuestras costas cuando cruza el Atlántico» $(1905,13)$. Si el pobre hidalgo -«sediento de grandezas, cazador de gloria» (1905, 13)- simboliza la raza española, el símbolo de Galicia es el pobre siervo, «hastiado de expoliaciones, que deja la patria chica, estos ambientes, para comer mejor y volver a ellos a ser señor en ellos» $(1905,13)$. Así, frente a un don Quijote que en acción es expansivo, activo y tenaz, el gallego -en su vulpinismo- «se repliega sobre sí, se esconde tras matorrales de hipocresía y convención» (1905, 13). La identidad gallega ha sido forjada en el temor, el engaño, la renuncia a cualquier empresa ambiciosa: «No tiene sed de cosas grandes, ni hambre de ideales redentores. Espera su vivir y no desespera si no vive» $(1905,13)$. Pero esa visión conduce a una cuestión absolutamente crucial en el momento en que se publica El centenario: «¿Se puede hacer injerto de vulpejería y quijotismo?» $(1905,13)$. O en otras palabras, ¿se puede cambiar, dando origen a un espíritu, un alma, una identidad diferente, capaz de engastar las inclinaciones zorrunas en la locura quijotesca, o la facilidad para inventar empresas del hidalgo castellano con la brutalidad y la astucia del siervo gallego? Luis André responde con firmeza: «Se puede y se debe hacer por selección y evolución darwiniana» $(1905,13)$. Y de ahí el programa que propone el autor, y que tiene mucho de planteamiento regeneracionista, porque Galicia está a sus ojos en un momento de parálisis:

Infundamos el ideal de un nuevo quijotismo en nuestras almas [...] Hay que enloquecer frenéticamente el alma y enardecer sobrehumanamente el corazón para proseguir nuestra marcha ascendente, con voluntad de redención e idea de rebeldia $(1905,13-14)$.

Como escribiría en el «Prólogo» a Galleguismo, Galicia es «tierra corrompida y desvalida presa y víctima de amos sin alma, carne de tiranos» (1931, 9). La selección de las especies darwiniana debe convertir al lobo y al zorro -al lobizorro- en homo sapiens et pervivens. Porque conviene precisar, siguiendo las ideas que articula el autor en el «Prólogo» mencionado, que el enemigo del galleguismo es

Ese sanedrín gallego, de pseudo intelectuales, de profesionales de la política y de la clerecía y del militarismo y de la toga -las clases directoras de Galicia-, que tienen por ámbito el templo profanado de la vida pública, convertido en madriguera y caverna de impudicias y latrocinios, esa farsa cruel y sangrienta de la gallegada, adjetivada a la casta de extranjeros y mestizos desclasados (fenicios, semitas, orejos) $(1905,12)$.

Esa gente, repito, las clases directoras de Galicia, «es la corruptora del pueblo» $(1905,13)$. Así, delimita con encono y compromiso su posicionamiento favorable al pueblo gallego pero enfrentado a las élites que rigen de facto los destinos de la tierra.

Luis André reflexionaría en varias ocasiones sobre el estatuto de Galicia $\mathrm{y}$ otros asuntos relacionados con el galleguismo. Nos interesa particularmen- 
te su trabajo «¿Somos una nación o somos una colonia?» en Galleguismo, donde arranca de una definición de Fischbach sobre la nación en Teoría general del Estado, para imaginarla como «una comunidad humana, articulada por la raza, la lengua y la cultura, y por la conciencia de una solidaridad interdependiente, de una solidaridad colectiva» $(1931,251)$, garantizada políticamente en la forma de un Estado, que puede bien ahogar a la nación, bien convertirse en su forma más adecuada y perfecta. Pero el análisis de la realidad social y psicológica del alma gallega le conduce a la conclusión de que las élites han convertido «en colonia la nación gallega» $(1931,256)$. Como consecuencia, escribe: «Ha sonado la hora de la emancipación de los siervos. Galicia, con una conciencia nacional sensible, convencida y resuelta para la acción, siente la nostalgia de su aurora de libertad merecida y no lograda» $(1931,257)$. En síntesis, no es el planteamiento del nacionalismo clásico que contrapone una nación (oprimida, explotada y reprimida) a otra (la opresora, explotadora y represora), sino sobre todo un enfrentamiento entre el pueblo bajo y las clases dominantes de la propia región/nación.

Ramón Bernárdez (1838-1911), licenciado en Derecho, sacerdote que llegaría a abad de la Colegiata de La Coruña, miembro de la Real Academia Galega y simpatizante del regionalismo gallego liberal, participaría en la constitución en 1907 de Solidaridad Gallega, organización agrarista y anticaciquil. En «Quijotes y Sanchos» arranca de la contraposición, ya firmemente establecida entre los comentaristas de la obra cervantina, entre el idealista caballero y el realista escudero, que Bernárdez califica de «las dos razas más dañinas de la sociedad: la raza de los delirantes y la de los pastranes» (1905, 16). Si la voz delirante es castellana, pastranes es voz gallega que alude, según el diccionario de la Real Academia Galega, a persona sucia, de aspecto descuidado, que no se lava. Don Quijote es, para Bernárdez, «desequilibrado, fanático, energúmeno, hambriento de grandezas y dominación [...] soñador empedernido, ipobre víctima de una civilización estrafalaria y fantasmagórica!» $(1905,16)$. Por el contrario, Sancho es «aquel cuco vulgar y chabacano [...] egoistonzuelo agreste, [...] majadero socarrón» $(1905,16)$. Y lo que parece un comentario puntual sobre el Quijote termina con una queja porque quijotes y sanchos «continúan siendo las razas dominantes de la sociedad... española» $(1905,16)$. En esos puntos suspensivos inscribe el autor su distanciamiento psicológico, mental y político de la realidad de España, y el lector debe suponer que esa no es la misma realidad de... Galicia.

Probablemente el último galleguista que inscribe con cierta claridad su ideología en esta celebración cervantina es Salvador Golpe (1850-1909), regionalista conservador que también participaría en la Real Academia Galega, autor de «La patria según el Quijote», donde reflexiona sobre la diferencia entre la patria grande y la patria chica. Pero es muy fuerte su posicionamiento regionalista ya desde el primer párrafo: «Son tercos, cual ninguno, los españolistas puros: los partidarios intransigentes de la Patria grande, única, uniforme, intangible e infrangible -a pesar de la pérdida de las colonias» $(1905,29)$. Podemos describir a esos españolistas siguiendo a Martínez Mur- 
guía, quien en el «Prólogo» a su obra El regionalismo gallego, publicada en 1889, escribe:

La exageración del poder central tenía a la postre que dar sus resultados: negando por completo el derecho a la vida a las provincias, la metrópoli solo ha ganado sus odios, cortándole sus naturales vías de expansión, solo ha conseguido que las ansias de libertad y de mejoramiento local estallen ruidosamente; en una palabra, el sistema de absorción empleado por los poderes públicos desde el siglo XVI ha servido únicamente para que los antiguos estados ibéricos echen de menos la independencia que les reconocieron todos sus reyes $(1889$, iii),

una realidad, la del centralismo, que ha desencadenado, según Murguía, las reivindicaciones históricas de Cataluña, Navarra, Aragón e incluso la propia Castilla. Sin enfatizar la exaltación de su propia patria pequeña, lo que articula Golpe es un ataque frontal contra el centralismo unionista, esos españolistas que no parecen haber procesado consecuentemente la final desmembración de lo que un siglo atrás todavía era un imperio. Acudiendo a Taine, Duroy, Pi y Margall, Mañé y Flaquer, Robert, Silvela «y todos los regionalistas españoles, catalanes, aragoneses, navarros, vascongados, gallegos, etc.» $(1905,29)$, pone sobre el tapete la diferencia entre «una patria grande y otra pequeña, y que ambas son la misma, querida y respetada con idolatría, siquiera una sea más grande en intensidad y la otra en extensión», enfrentando esa conciencia a la posición unionista, «ellos siguen, erre que erre, en que ha de ser una sola, sin diferencias ni preferencias» $(1905,29)$. Y si para la cuestión de la lengua vernácula se recurre a la segunda parte, capítulo XVI, que ya hemos visto, para la cuestión de la patria también se volverá a la segunda parte, pero al capítulo LIV, donde el morisco Ricote expresa su melancolía tras la expulsión, aunque contrastando esas ideas con otras dispersas a lo largo de la novela y que ponen de relieve la importancia y significación de la patria pequeña. El patriotismo debe incluir a la patria pequeña porque es ahí donde se alberga y condensa la intensidad del sentimiento patriótico. Ante la patria grande, dice Golpe, «se alzarán furiosos y sanguinarios los Quijotes de la moderna edad, dispuestos a agrandarla conquistando imperios», pero ante la patria pequeña -la Región- «sin faltar a la primera, se arrodillarán humildes, velando la cuna de sus hijos, los Sanchos de todas las edades») (1905, $30)$.

\section{OTRAS MIRADAS}

Como decíamos al comienzo, no son solo los galleguistas quienes articulan una postura en la que Cervantes y el Quijote sirven como referencia para reivindicar una realidad regional/nacional diferente a la española. También hay miradas claramente españolistas. Y así, el liberal Alfredo Vicenti, en «La 
mujer de Sancho» se coloca en una posición diferente para contemplar la realidad de España. Para Vicenti, la mujer de Sancho, Teresa Panza, «personifica la atrofia del paladar moral», el tipo femenino que «mayor daño ha causado a la sociedad española» $(1905,15)$. Vicenti parece acusar metonímicamente a Teresa Panza, con una mirada machista, misógina e incluso antifemenina, de ejercer una opresión amoral sobre los varones en la medida en que la exigencia de que actúen como machos proveedores se sitúa más allá de cualquier valor moral. «Según ella, muy por encima de toda ética y de todo honor debe de estar, para el jefe de la casa, la obligación de traer un plato más a la mesa y una prenda más al ropero de la familia» $(1905,16)$. Para curarse en salud, sin embargo, reconoce que en los momentos extraordinarios, en «las horas dramáticas y excepcionales [...] raya la virtud de nuestras mujeres en los más altos vértices de la abnegación, del desinterés y del heroísmo» $(1905,16)$, pero la rutina marca y determina el materialismo amoral de la vida cotidiana. Y esa mujer sin valores ni criterio moral es la que, concretada en Catalina de Palacios, hizo la vida imposible de Cervantes: «Esposa amable, compañera descontentadiza, madre estéril» $(1905,16)$.

La perspectiva de Segundo Moreno Barcia (1841-1909), significado republicano federal que participó en la redacción del Proyecto de Constitución para el Estado Galaico en 1887, tal y como se formula en su artículo «El símbolo», es tal vez la que con más intensidad se concentra en la política española posterior a 1898. Y es la que con más firmeza critica la deriva de los gobiernos que habían llevado a la derrota de ese año. El «excéntrico personaje» que es don Quijote se recorta «como una personificación tan exacta como sorprendente de la nacionalidad española, que no parece sino que Cervantes hubo de vaciar su héroe en los moldes de su raza» $(1905,17)$. Como otros antes que él, Moreno Barcia ve en el hidalgo una representación magnífica de la raza española. A partir de aquí, el asunto que se abre es la actitud del autor respecto a esa raza $\mathrm{o}$, en otros términos, de la nación que cobijó a esa raza, es decir, España. Una serie de cuestiones retóricas articula la reflexión del autor, en donde se entrelazan opiniones contundentes sobre esa nación: una «política brutal y suicida» $(1905,17)$ en su tratamiento de los agarenos y judíos, «una política de explotación, violencia y fanatismo» en su ocupación de América, que concluye con los desastres de Santiago y Cavite, una política de derroche y dilapidación «para alimentar la loca ambición de Carlos V» $(1905,17)$, una visión de la España de Felipe II en la que se le presenta como «caballero andante de la devoción al uso, vengador insensato de los pretendidos agravios inferidos por herejes, reformados y relapsos» $(1905,17)$, locura o delirio que sirvió de base a una política «de herir sin piedad ni descanso las provincias europeas del norte, siquiera hubieran de hundirse bajo montones de escombros, miseria, sangre y lágrimas la Nación con Portugal, esclavizada [...] y envuelta en tanta desdicha» (1905, 17). Los golpes y violencias que sufre don Quijote no son sino la imagen perfecta, según Moreno Barcia, de «la infeliz España [que] sucumbe bregando y muriendo por motivos que en manera alguna le interesaban» $(1905,17)$. Esa política de España no persiguió ninguna «finalidad grande, progresiva y gene- 
radora de todo bien público y privado» $(1905,17)$, sino todo lo contrario, «el aniquilamiento y la vergüenza ante la realidad y la Historia» $(1905,17)$, que encontró su símbolo estupendo «para acabar ignominiosamente con Carlos II en la imbecilidad o el hechizo, provocado y sostenido por monjas y frailes inaprensivos» $(1905,17)$. El discurso anticlerical, progresista y republicano se presenta frontalmente, dando cabida a algunos de los mitos y mitologemas propios de la historiografía liberal. Pero, al mismo tiempo, denunciando una historia política de la que ni su partido ni su nación quieren sentirse partícipes. Moreno Barcia cierra su colaboración con una nota de esperanza en la regeneración y la reorientación política de España, única estrategia que permitirá que el Quijote no sea el símbolo perfecto de la muerte de la nación española.

Un caso particular es el de Emilia Pardo Bazán, a quien Rodríguez Santamaría no califica políticamente, sino que para él es «unha soa muller», que «contribuíu cunha prosa irónica, pero bastante insubstancial», a pesar de las «moitas reflexións sensatas» $(2005,77)$ que la novelista ofrecerá sobre el Quijote. Es cierto que esta colaboración con El centenario -titulada «Cervantes periodista a la moderna»- no es precisamente el trabajo más enjundioso de la novelista sobre Cervantes, y con ello quiero decir que no fue en la celebración del tercer centenario cuando Pardo Bazán aportó realmente una visión profunda e interesante sobre el Quijote y su autor. En su caso habría que esperar a otro centenario, esta vez el tercero de la muerte de Miguel de Cervantes en 1916. Y, más específicamente, a sus dos conferencias en el Ateneo de Madrid, de 23 de febrero y 8 de marzo, y a su conferencia en Albacete, de 24 de abril, textos estudiados -el de Albacete, también editadocon minucia y perspicacia por Cristina Patiño Eirín (2001), así como -en un trabajo mucho más amplio sobre la oratoria de Pardo Bazán- por M. ${ }^{\mathrm{a}}$ Aránzazu Guzmán Guzmán en su tesis doctoral $(2014)^{2}$. Las dos conferencias del Ateneo, publicadas a cinco columnas en El Imparcial de 25 de febrero y 9 de marzo, exploran y comparan la posición del Quijote entre las obras capitales del espíritu humano, y concluye el 9 de marzo, en un tono que resonará en el Juan de Mairena machadiano, que Cervantes «ha dejado en el Quijote la cifra del alma humana, aspirando al ideal y sujeta por la materia y por ella amarrada a la tierra mísera». Pero esa alma humana es, también, simbólicamente «la perfecta identificación con el alma de la patria». Y, al igual que tantos otros letrados y literatos, arrima el ascua quijotesca a la sardina regeneracionista, o al menos a la terapia postraumática:

\footnotetext{
Y sírvanos esta convicción de consuelo en tantos patrióticos dolores como hemos sufrido, y ojalá no tengamos nuevas ocasiones de sufrir. Esta es la excelencia del espíritu: no consiente violencia ni exacción; y, por lo tanto, el Quijote no puede quitárnoslo nadie; nuestro es por los siglos de los siglos, así truenen cañones, corra sangre y caiga sobre nosotros el mundo entero. ¡Nuestro, nuestro, el buen Hidalgo!
}

2. Guzmán Guzmán, M. ${ }^{a}$ Aránzazu. 2014. La oratoria de Emilia Pardo Bazán (Discursos, Conferencias, Lecturas Públicas), tesis doctoral, Universidad Nacional de Educación a Distancia (UNED). 
Juan Barcia Caballero (1852-1926), médico vinculado a la Asociación Regionalista Gallega de Martínez Murguía, que fue director del Hospital de San Roque y del Manicomio de Conxo en Santiago, defiende en «El centenario del Quijote» la participación gallega por una cuestión muy simple: el patriotismo. Merece la pena recordar que en la Asociación Regionalista Gallega, activa entre 1890 y 1892, fusionó las dos tendencias dominantes en el regionalismo, una liberal y otra tradicional y conservadora. Es fácil suponer que Barcia Caballero formaba parte de esta segunda, aunque en su colaboración a El centenario muestra con claridad una faceta regeneracionista que no es estrictamente gallega, sino española. Porque el patriotismo del que habla no tiene nada de específicamente regional, sino que se destaca como una afirmación españolista. El Quijote, en efecto, es una obra excepcional que ha aportado una resonancia indiscutible en la visibilidad y el nombre de España. Sobre esa base, el Quijote parece servir como fuente para «levantar el espíritu patrio en los tiempos que corremos, cuando la necesidad de nuestra regeneración es cosa aceptada por todos y por todos reclamada» $(1905,12)$. El regeneracionismo, adelantado por Evaristo Ventosa en 1860 y articulado extensivamente por algunos escritores de la generación del 98, recurre por sistema al Quijote en una dirección u otra (Varea Olea 2003). Algo muy parecido sucede con José Rodríguez Carracido (1856-1928), farmacéutico, bioquímico y político, que escribe «En defensa de Sancho» para exaltar la imagen de Sancho como ejemplo que conviene seguir para la regeneración nacional y capitalista -y parece ser que la nación para él es España, no Galicia-, pues frente a la «dejadez nacional» $(1905,12)$ lo que precisa la sociedad es un pueblo dispuesto a enriquecerse honradamente porque eso «es contribuir al bien de todos» $(1905,12)$. Para Carracido, la respuesta a la situación es un pueblo que absorba por sus raíces «los jugos de la realidad» $(1905,13)$.

Republicano, masón y obrerista, Santiago de la Iglesia Santos (1851-1931), médico, naturalista y maestro, utiliza su colaboración, «Don Quijote redivivo», para hablarnos de un Quijote gallego, que no leyó libros de caballerías sino los de Proudhon, Marx, Kropotkin y Tolstói, y que quiso poner en práctica por todas partes lo que había leído «promoviendo y excitando huelgas, motines, asonadas y manifestaciones sin cuento» $(1905,22)$. Este Quijote no tiene otra dama -otro idealizado amor- que la Libertad, Acracia o Amor Universal. Así, más allá de las razas y las naciones, su texto nos habla de la causa universal de la lucha obrera por la igualdad, la libertad y la fraternidad. Dice el autor que él conoció a este Quijote y que calla su nombre por veneración. Xesús Alonso Montero $(2005,16-17)$ trató de identificar a ese Quijote y llegó a la conclusión, por los estudios de María Rosa Saurín de la Iglesia, de que se trataba de Benigno de la Iglesia González (1836-1872), identificación que no sabemos qué valor intelectual pueda tener pero que obviamente permite devolver a este luchador de la causa obrera, internacionalista y utópica.

Solo Ramón López de Vicuña (1852-1909), miembro de la Real Academia de la Historia, asume lo que pudiéramos llamar una visión centralista y españolista de Cervantes y el Quijote, que en su opinión es 
el monumento erigido al genio nacional, y su héroe, la representación simbólica del espíritu español, hidalgo, valiente, generoso, aventurero, enamorado del ideal más bien que de la realidad, $\mathrm{y}$, ¿por qué no decirlo?, las más de las veces falto de juicio, loco, tan loco y tan falto de juicio como don Quijote y, como él, desafortunado en sus temerarias aventuras $(1905,15)$.

\section{CONCLUSIONES}

En el nuevo contexto cultural, ideológico, geopolítico y económico, hemos podido ver cómo, coincidiendo con el tercer centenario de la publicación de la primera parte del Quijote, las fuerzas políticas de toda adscripción se acercan a la figura de Cervantes y su obra singular para marcar la fecha sea como capital cultural que refuerce los programas centralistas, unionistas y conservadores, sea para apoyar a las corrientes críticas y progresistas, sea para servir como referencia en las formulaciones y propuestas de los movimientos regionalistas/nacionalistas de las naciones históricas de la periferia. Más específicamente, hemos visto cómo, al calor del regionalismo galleguista, la conmemoración cervantina y quijotesca se convirtió en un momento de alta carga simbólica para darle visibilidad y una dimensión pública mayor a algunos de sus planteamientos clave, relacionados sin duda con lo que más tarde iría configurando el nacionalismo político gallego.

$\mathrm{Y}$, si es cierto que El centenario es la producción más notable de la participación gallega en la celebración quijotesca, también es verdad que no fue la única, como ya hemos indicado. Porque, tras la intensa intervención del gobierno y las instancias institucionales en el tricentenario, Miguel Sawa hermano de Alejandro Sawa, periodista y escritor, director del semanario satírico progresista Don Quijote - y Pablo Becerra dirigen la publicación de la Crónica del Centenario de «Don Quijote», en Madrid, Establecimiento tipográfico de Antonio Marzo, 1905, un volumen de 559 páginas numeradas donde se repertorian todas las actividades vinculadas a la celebración. Y es en esa publicación donde encontramos referencias precisas a las diferentes participaciones que Galicia ofreció para conmemorar el aniversario, sobre las que volveremos en otra ocasión.

\section{BIBLIOGRAFÍA CITADA}

Aizpuru, Mikel. 2000. «Vascófilos y bertsolaris, coformadores del nacionalismo vasco en el último tercio del siglo XIX». Gerónimo de Uztariz 16: 59-72.

Alonso Montero, Xesús. 2005. «O Quixote e os intelectuais galegos de 1905». La Voz de Galicia. Culturas, suplemento 8 de enero: 16-17.

Álvarez Junco, José. 2001. Mater Dolorosa. La idea de España en el siglo XIX. Madrid: Taurus. 
Álvarez Junco, José. 2016. Dioses útiles. Naciones y nacionalismos. Barcelona: Galaxia Gutenberg.

Archilés, Ferran. 2007. «¿Experiencias de nación? Nacionalización e identidades en la España restauracionista». En Construir España. Nacionalismo español y procesos de nacionalización, ed. Javier Moreno, 127-151. Madrid: Centro de Estudios Políticos y Constitucionales.

Barcia Caballero, Juan. 1905. «El centenario del Quijote». En El centenario del «Quijote» en Galicia, 12. La Coruña: Publicación de la Liga de Amigos de La Coruña.

Bell, David A. 2003. The Cult of the Nation in France. Inventing Nationalism, 1680-1800. Cambridge: Harvard University Press.

Bernárdez, Ramón. 1905. «Quijotes y Sanchos». En El centenario del «Quijote» en Galicia, 16. La Coruña: Publicación de la Liga de Amigos de La Coruña.

Bourdieu, Pierre. 1979. «Les trois états du capital culturel». Actes de la recherche en sciences sociales 30: 3-6.

Bush, Peter. 1980. «Galdós y Vida Nueva». Monteagudo 68: 5-11.

Carré Aldao, Eugenio. 1905. «Cervantes, rexionalista». En El centenario del «Quijote» en Galicia, 16-17. La Coruña: Publicación de la Liga de Amigos de La Coruña.

Colley, Linda. 1992. Britons: Forging the Nation, 1707-1837. Newark: Yale University Press.

Fusi, Juan Pablo y Jordi Palafox. 1997. España: 1808-1996. El desafio de la modernidad. Madrid: Espasa-Calpe.

Gillis, John R. 1994. «Introduction. Memory and Identity: The History of a Relationship». En Commemorations. The Politics of National Identity, ed. John R. Gillis, 3-24. Princeton: Princeton University Press.

Golpe, Salvador. 1905. «La patria según el Quijote». En El centenario del «Quijote» en Galicia, 29-30. La Coruña: Publicación de la Liga de Amigos de La Coruña.

González Beramendi, Justo. 1997. El nacionalismo gallego. Madrid: ArcoLibros.

Iglesia Santos, Santiago de la. 1905. «Don Quijote redivivo». En El centenario del «Quijote» en Galicia, 20-23. La Coruña: Publicación de la Liga de Amigos de La Coruña.

López de Vicuña, Ramón. 1905. El Quijote y el espíritu nacional». En El centenario del «Quijote» en Galicia, 14-15. La Coruña: Publicación de la Liga de Amigos de La Coruña.

Lugrís Freire, Manuel. 1905. «Cervantes y Camoens». En El centenario del «Quijote» en Galicia, 26-28. La Coruña: Publicación de la Liga de Amigos de La Coruña.

Luis André, Eloy. 1905. «Galleguismo y quijotismo». En El centenario del «Quijote» en Galicia, 13-14. La Coruña: Publicación de la Liga de Amigos de La Coruña.

Luis André, Eloy. 1931. Galleguismo. Lucha por la personalidad nacional y la cultura (Ensayos). Madrid: Imprenta J. Murillo.

Maíz Suárez, Ramón. 1996. «Nación de Breogán: oportunidades políticas y estrategias enmarcadoras en el movimiento nacionalista gallego (1886-1996)». Revista de Estudios Políticos (Nueva Época) 92: 33-75.

Martínez Murguía, Manuel. 1899. El regionalismo gallego. Habana: Imprenta y Papelería «La Universal».

Miralles, Xavier Andreu. 2016. «La nacionalización española en el siglo XIX. Un nuevo balance». Spagna Contemporanea 49: 169-184.

Moreno Barcia, Segundo. 1905. «El símbolo». En El centenario del «Quijote» en Galicia, 17. La Coruña: Publicación de la Liga de Amigos de La Coruña.

Moreno Luzón, Javier. 2007. «Mitos de la España inmortal. Conmemoraciones y nacionalismo español en el siglo XX». Claves de la razón práctica 174: 26-35.

Núñez Seixas, Xosé M. 2002. «Orígenes, desarrollo y mutaciones del nacionalismo gallego (1840-1982)». En Les nacionalismes en Espagne: de l'État libéral à l'état des 
autonomies (1876-1978), ed. Francisco Campuzano, 331-365. Montpellier: Presses universitaires de la Méditerranée. Accesible en: <https://books.openedition.org/ pulm/787?lang=en>". Paginación independiente.

Patiño Eirín, Cristina. 2001. «Cervantes en la obra de Pardo Bazán». En Volver a Cervantes. Actas del IV Congreso Internacional de la Asociación de Cervantistas, Lepanto 1-8 de octubre de 2000, coord. Antonio Pablo Bernat Vistarini, t. 2, 1220-1228. Palma de Mallorca: Universitat de les Illes Balears.

Pérez Magallón, Jesús. 2015. Cervantes, monumento de la nación: problemas de identidad y cultura. Madrid: Cátedra.

Piguet, Marie-France. 2000. «Observation et histoire: Race chez Amédée Thierry et William F. Edwards». L'Homme 153: 93-106.

Quiroga, Alejandro. 2013. «La nacionalización en España. Una propuesta teórica». Ayer 90: 17-38.

Ribalta, Aurelio. 1905. «De cómo los gallegos debemos leer el Quijote». En El centenario del «Quijote» en Galicia, 10-12. La Coruña: Publicación de la Liga de Amigos de La Coruña.

Rodríguez Carracido, José. 1905. «En defensa de Sancho». En El centenario del «Quijote» en Galicia, 12-13. La Coruña: Publicación de la Liga de Amigos de La Coruña.

Rodríguez Santamaría, Xoán Pastor. 2005. Cervantes e o Quixote en Galicia. La Coruña: Noia.

Sawa, Miguel y Pablo Becerra, eds. 1905. Crónica del Centenario de «Don Quijote». Madrid: Establecimiento tipográfico de Antonio Marzo.

Smith, Anthony. 1991. National Identity. Reno: University of Nevada Press.

Storm, Eric. 2008. «El Ateneo de Madrid y el tercer centenario del Quijote de 1905». En Don Quijote en el Ateneo de Madrid, ed. Nuria Martínez de Castilla Muñoz, 11-47. Madrid: Sociedad Estatal de Conmemoraciones.

Túñez, Narciso. 1905. «Justicia y gratitud». En El centenario del «Quijote» en Galicia, 31. La Coruña: Publicación de la Liga de Amigos de La Coruña.

Valis, Nöel. 2002. The Culture of Cursilería. Durham: Duke University Press.

Varea Olea, M. Ángeles. 2003. Don Quijote, mitologema nacional. Alcalá de Henares: Centro de Estudios Cervantinos.

Vicenti, Alfredo. 1905. «La mujer de Sancho». En El centenario del «Quijote» en Galicia, 15-16. La Coruña: Publicación de la Liga de Amigos de La Coruña.

Recibido: 3 de abril de 2020

Aceptado: 1 de julio de 2020 
